\title{
ESQUISTOSSOMOSE MANSÔNICA HEPATOESPLÊNICA: uma doença trágica
}

"Foi um rio que passou em minha vida e meu coração se deixou levar"

Paulinho da Viola

DESCRITOR - Esquistossomose mansônica.

Os rios assumem uma participação importante na formação dos povos e de suas culturas. Exemplos típicos são o Tigre, o Eufrates ou o Jordão. São bíblicos e atuantes na formação do pensamento religioso de muçulmanos, judeus e cristãos. Também foram relevantes para Cristóvão Colombo, que descreveu o Novo Mundo como um paraíso situado na Terra, onde se podia beber na Fonte da Juventude e de onde a água corria em quatro gigantescos rios, interrogando-se se o Orinoco não tinha sua nascente no Paraíso ou o Ganges (tão importante para o hinduísmo) não seria um dos quatro grandes rios do mundo ${ }^{(4)}$.

$\mathrm{Na}$ constituição do povo brasileiro assumem conotação as bacias hidrográficas formadas pelo Amazonas, Paraná, Paraíba e pelo São Francisco. Mas, para os poetas como Armando Nogueira, mesmo os pequenos rios, por exemplo o Acre, no seu Xapuri, representa o "meu Jordão, água da minha purificação, pia primordial, feito para amar, para navegar, para refletir em suas águas à sombra da samaúma e da longa castanheira em seus arredores, de poesia misteriosa e agradável'(9).

Mas, alguns rios são poluídos e juntam tranqueiras em suas margens e em suas curvas ${ }^{(1)}$, comportamento que gera poesia não luminosa, mas trágica, para nordestinos ribeirinhos das zonas da mata de Alagoas, Sergipe, Bahia, Pernambuco, Rio Grande do Norte e Minas Gerais. Neles prolifera o caramujo do gênero Biomphalaria glabrata, responsável pela infestação de 8 a 10 milhões de indivíduos potencialmente capazes de evoluírem com a forma hepatoesplênica da esquistossomose mansônica, doença geradora de hipertensão portal e de elevados índices de morbimortalidade.

Aprofundando-se no entendimento do problema, pesquisadores sergipanos $^{(1)}$, exceto um deles (MCCM), valendo-se de avaliação e mensuração do fluxo sangüíneo portal, através de Doppler duplex colorido, definiram que, quanto maior seu valor, mais elevado apresenta-se o nível sérico de gamaglutamiltransferase (GGT). Tal modificação não foi observada em outras enzimas hepáticas, tais como transaminases glutâmico-pirúvica e/ou oxalacética, e fosfatase alcalina, ou nos parâmetros que expressam síntese hepática como albumina, bilirrubina direta, ou atividade de protrombina. Relacionam esse comportamento hemodinâmico com a colestase que exibem, não concluindo que possa também decorrer de alterações anatômicas da própria árvore biliar que apresentam ${ }^{(5,12)}$, pois estudos anatomopatológicos de fígado não foram realizados em seus pacientes.

Outro aspecto que os próprios autores realçam é que estas modificações foram mais nítidas nos doentes não-operados, mas sem que qualquer dos grupos estudados atingisse significância estatística, com as medidas de fluxo sendo realizadas com intervalo mínimo de 15 dias, após episódio de hemorragia digestiva alta. Será que tal comportamento bioquímico não refletiria simplesmente o desencadeador de eventos de regeneração hepatocelular, seguindo-se ao sangramento digestivo e a conseqüente isquemia hepática que certamente apresentaram? Por isso, achamos que seria interessante que tais níveis séricos de GGT fossem mensurados como forma de comparação, cerca de 120 ou 180 dias, após a primeira medida de fluxo, agora em fase mais distante das situações de estresse em que se encontravam. Além disso, também relevante seria a correlação dos valores séricos da GGT com o índice de congestão portal, conforme proposto por LEMOS et al. ${ }^{(6)}$, em 2003, outro índice que, avaliado pela dopplerfluxometria em esquistossomóticos, permite também caracterizar as alterações do fluxo hepático que eles apresentam.

A esse respeito deve-se ressaltar que a esquistossomose mansônica hepatoesplênica é uma doença predominantemente vascular, mesenquimal e não-parenquimatosa, nos quais a função hepatocelular de 
síntese encontra-se bem preservada. Excepcionalmente, observamse fenômenos de necrose e regeneração de hepatócitos e, quando esses estão presentes, são decorrência das presenças séricas ou teciduais dos vírus das hepatites B e C. Associadamente, eles evoluem com expansão de espaços portais e presença de faixas fibróticas, oclusão de ramos portais e neoformação vascular angiomatóide (sinal de Bogliolo), modificações relacionadas às presenças de ovos do vermes embolizados, causadores de vasculite aguda e lesão de células endoteliais, responsáveis por migração de monócitos, liberadores de fatores celulares específicos, promotores de edema parietal e degradação da matriz subendotelial, levando à formação eventual de granulomas. Como resposta a essa hiperantigenemia gerada, instalam-se glomerulopatia, hipertensão pulmonar e comprometimento de ductos biliares. Nessa última eventualidade, em alguns casos, inclusive com evidências de sinais colangiográficos típicos, tais como estenoses, subestenoses e dilatações comumente observados na colangite esclerosante primária ${ }^{(12)}$ e que histologicamente se traduz pela formação de espesso manguito fibroso disposto em torno dos ductos biliares. Indaga-se se tais modificações não se acentuam, desde que existissem situações redutoras da perfusão hepática, tal como se observa após a hemorragia digestiva ou no sofrimento arterial póstransplante de fígado. São aspectos que seriam melhor comprovados se tais pacientes tivessem sido submetidos a biopsia hepática, através da qual poderia afastar essas possíveis associações e tornaria mais elegante a publicação que motiva este editorial, embora não diminua a importância da pesquisa que abre novas perspectivas na correlação entre fluxo sangüíneo e comportamento de níveis séricos de enzimas hepáticas.

São esses pacientes que, ao serem avaliados em termos sociais e epidemiológicos, mostram tendência evolutiva aterradora, observada mesmo naqueles que fugindo das zonas mais pobres do País, no nordeste brasileiro, migram para o sul maravilha, na busca de um Eldorado utópico, comportando-se como Édipos, que se afastam de suas Jocastas (mãe Terra original), na tentativa de fuga de certos planos ocultos transcendentais, de sua própria providência, de seus fados ou de seus trágicos destinos ${ }^{(3,7,8,10)}$, com a aniquilação do homem processando-se através de forças inelutáveis ${ }^{(2)}$.

Adávio de OLIVEIRA-e-SILVA* Luiz Augusto Carneiro D`ALBUQUERQUE**

Oliveira-e-Silva A, D'Albuquerque LAC. Hepatosplenic schistosomiasis mansoni: a tragic disease. Arq Gastroenterol 2003; 40(4):201-202.

HEADING - Schistosomiasis mansoni.

\section{REFERÊNCIAS BIBLIOGRÁFICAS}

1. Alves Jr A, Fontes DA, Melo VA, Machado MCC, Cruz JF, Santos EAS. Hipertensão portal esquistossomótica: influências do fluxo sangüíneo portal nos níveis séricos das enzimas hepáticas. Arq Gastroenterol 2003;40:-

2. Alves de Lima M. Dereton reforça o trágico em "Agreste". Estado de S. Paulo, Caderno 2, p. D9, 23 de janeiro de 2004

3. Bulfinch T. A esfinge. In: Bulfinch T. O livro de ouro da mitologia. São Paulo: Ediouro; 2002. p.152.

4. Carriére JC. Capítulo 1. In: Carriére JC, editor. A controvérsia. São Paulo: Companhia das Letras; 2003. p. 9.

5. el-Garim AA. Schistosomiasis. Digestion 1998;59:589-605.

6. Lemos RS, Ferraz AB, Oliveira IRS, Ferraz EM. Dopplerfluxometria em portadores de esquistossomose hepatoesplênica (EHE): aspectos técnicos relacionados ao cálculo do fluxo sangüíneo portal e índice de congestão. $\mathrm{ABCD}$ Arq Bras Cir Dig 2003;16:134-8.

7. Maffesoli M. Uma vida sem objetivo. A força do destino. O retorno cíclico. In: Maffesoli M. O instante eterno. São Paulo: Zouk; 2003. p.17.

8. Most GW. Da tragédia ao trágico. In: Rosenfield DL. Filosofia \& literatura: o trágico. Rio de Janeiro: Jorge Zahar; 2003. p.174.

9. Nogueira A. Sem ciúmes. Jornal O Estado de São Paulo, p. E2, 31 de dezembro de 2003.

10. Salis VD. Édipo rei. In: Salis VD. Mitologia viva. S. Paulo: Nova Alexandria; 2003. p. 174 .

11. Trigo L. Memória encardida. Bravo, 76, p. 101, 2004

12. Vianna MR, Gayotto LCC, Telma R, Santos M, Ferreira Alves VA, Fukushima J, de Brito T. Intrahepatic bile duct changes in human hepatosplenic schistosomiasis mansoni. Liver 1989;9:100-9.

\footnotetext{
* Departamento de Gastroenterologia da Faculdade de Medicina da Universidade de São Paulo e ** CETEFI - Centro Terapêutico Especializado em Fígado do Hospital da Beneficência Portuguesa de São Paulo, SP.
} 